Address for Correspondence: Dr. Gautam Rawal,

Flat No. 417, Dhruva Apartments, Plot no. 4, I P Extension, Patparganj, Delhi 110092, India.

Email: drgautamrawal@hotmail.com

\begin{tabular}{|l|}
\hline Access this article online \\
\hline $\begin{array}{l}\text { Website: } \\
\text { www.intern-med.com }\end{array}$ \\
\hline $\begin{array}{l}\text { DOI: } \\
\text { 10.1515/jtim-2016-0012 }\end{array}$ \\
\hline Quick Response Code: \\
\hline \\
\\
\\
\end{tabular}

\title{
Acute respiratory distress syndrome: An update and review
}

\author{
Gautam Rawal $^{1}$, Sankalp Yadav ${ }^{2}$, Raj Kumar ${ }^{3}$ \\ ${ }^{1}$ Attending Consultant, Department of Respiratory Intensive Care, Max Super Specialty Hospital, Saket, \\ New Delhi, India; \\ ${ }^{2}$ General Duty Medical Officer-II, Department of Medicine \& TB, Chest Clinic Moti Nagar, North MCD, \\ New Delhi, India; \\ ${ }^{3}$ Senior Consultant and Incharge, Department of Respiratory Intensive Care, Max Super Specialty Hospital, \\ Saket, New Delhi, India
}

\section{ABSTRACT}

Acute respiratory distress syndrome (ARDS) is a life threatening condition characterized by severe hypoxemia due to pulmonary gas exchange failure and was first recognized in 1960 s. Since its first description, it has undergone intensive research in the past few decades to understand its pathogenesis and therapies. Despite this, the recommended therapies to decrease mortality in ARDS remain limited and include low-tidal volume mechanical ventilation, prone ventilation and recently,the ECMO rescue therapy in extreme cases. This review article will summarize the key features of ARDS with a brief overview of the therapeutic options in the management of ARDS.

Key words: acute respiratory distress syndrome (ARDS), the Berlin definition, ECMO

\section{INTRODUCTION}

Acute respiratory distress syndrome (ARDS) is an acute life threatening inflammatory lung injury manifested by hypoxia and stiff lungs due to increased pulmonary vascular permeability and almost always requiring mechanical ventilation support. ${ }^{[1]}$ ARDS represents an acute response to diverse provoking trigger factors and etiologies, resulting bilateral lung opacities on radiography and hypoxemia.

ARDS was first described by Ashbaugh et al. in 1967, ${ }^{[2]}$ and since then there have been multiple studies addressing the various clinical aspects of the syndrome, its pathogenesis, risk factors, and treatment. However, despite the intense research, only few effective therapies for ARDS have been postulated, including the lung protection strategies.

In this review article, authors will summarize the key features of ARDS, a brief overview of the therapeutic options in the management of ARDS.

\section{DEFINITION}

ARDS was first defined in 1994 by the American-European Consensus Conference (AECC) as the acute onset of hypoxemia (arterial partial pressure of oxygen to fraction of inspired oxygen $\left[\mathrm{PaO}_{2} / \mathrm{FIO}_{2}\right]$ $\leq 200 \mathrm{~mm} \mathrm{Hg}$ ) with bilateral infiltrates on frontal chest radiograph, with no evidence of left atrial hypertension and acute lung injury (ALI) was defined using similar criteria, but having $\mathrm{PaO}_{2} / \mathrm{FIO}_{2} \leq 300 \mathrm{~mm}$ $\mathrm{Hg} \cdot{ }^{\left[{ }^{3}\right]}$ Over the years, with the ongoing research on this topic, issues regarding the validity and reliability of this definition emerged.

A panel of experts assembled in 2011 (an initiative of the European Society of Intensive Care Medicine endorsed by the American Thoracic Society and the Society of Critical Care Medicine) and developed the Berlin Definition of ARDS using a consensus process. ${ }^{[1]}$ The Berlin definition require all four criteria's to be present for diagnosis of ARDS (1) Timing: Respiratory symptoms must have begun within one week of a known clinical insult, or the 
patient must have new or worsening symptoms during the past week. (2) Chest imaging: Bilateral opacities consistent with pulmonary edema must be present on a chest radiograph or computed tomographic scan, which is not fully explained by pleural effusions, lobar collapse, lung collapse, or pulmonary nodules. (3) Origin of edema: The patient's respiratory failure must not be fully explained by cardiac failure or fluid overload. An objective assessment (e.g., echocardiography) to exclude hydrostatic pulmonary edema is required if no risk factors for ARDS are present. (4) Oxygenation: A moderate to severe impairment of oxygenation must be present, as defined by the $\mathrm{PaO}_{2} /$ $\mathrm{FiO}_{2}$ ratio.

The severity of the hypoxemia defines the severity of the ARDS: (1) Mild ARDS-The $\mathrm{PaO}_{2} / \mathrm{FiO}_{2}$ is $>200 \mathrm{mmHg}$, but $\leq 300 \mathrm{mmHg}$, on a ventilator with a positive endexpiratory pressure (PEEP) or continuous positive airway pressure $\geq 5 \mathrm{~cm} \mathrm{H}_{2} \mathrm{O}$. (2) Moderate ARDS-The $\mathrm{PaO}_{2} /$ $\mathrm{FiO}_{2}$ is $>100 \mathrm{mmHg}$, but $\leq 200 \mathrm{mmHg}$, on a ventilator with a PEEP $\geq 5 \mathrm{~cm} \mathrm{H}_{2} \mathrm{O}$. (3) Severe ARDS-The $\mathrm{PaO}_{2} /$ $\mathrm{FiO}_{2}$ is $\leq 100 \mathrm{mmHg}$ on a ventilator with a PEEP $\geq 5 \mathrm{~cm}$ $\mathrm{H}_{2} \mathrm{O}$.

Compared with the AECC definition, the Berlin Definition had a better prediction for mortality with increased percentage of mortality associated with increasing stages of ARDS: mild $27 \%$, moderate $32 \%$, and severe $45 \%$ with $95 \% \mathrm{CI}^{[1]}$

\section{PATHOPHYSIOLOGY AND RISK FACTORS}

ARDS occurs as a consequence of an alveolar injury due to various causes producing diffuse alveolar damage. This causes the release of pro-inflammatory cytokines [tumor necrosis factor, interleukin (IL)-1, IL-6, IL-8], which recruit neutrophils to the lungs, where they get activated and release toxic mediators (reactive oxygen species and proteases) that damage the capillary endothelium and alveolar epithelium leading to alveolar edema. ${ }^{[4]}$ This, eventually, leads to impairment of gas exchange, decreased lung compliance, and increased pulmonary arterial pressure.
Pathological stages: The initial stage is the exudative stage, characterized by diffuse alveolar damage. The second stage of proliferation develops after approximately 10-14 days, characterized by resolution of pulmonary edema, proliferation of type II alveolar cells, squamous metaplasia, interstitial infiltration by myofibroblasts, and early deposition of collagen. Some patients progress to the third stage of fibrosis, characterized by obliteration of normal lung architecture, diffuse fibrosis, and cyst formation. ${ }^{[5]}$

\section{CURRENT THERAPIES}

\section{Lung-protective ventilation}

Various trials have demonstrated that mechanical ventilation with lower tidal volumes (LTV) and airway pressures (tidal volume of $4-6 \mathrm{ml} / \mathrm{kg}$ predicted body weight and maintenance of plateau pressure between 25 and $30 \mathrm{~cm} \mathrm{H}_{2} \mathrm{O}$ ) reduces mortality in ALI and ARDS. ${ }^{[6]}$ This lung-protective ventilation preserves barrier properties of the alveolar endothelium and alveolar epithelium by preventing alveolar overdistension, which is one of the major causes of ventilator-induced lung injury. ${ }^{[6-11]}$ The concept of open lung ventilation uses low tidal volume with high PEEP with the rationale that LTV will minimize the damage due to overdistension while the high PEEP will minimize the cyclic atelectasis ${ }^{[6]}$, has been shown to have a beneficial effect on the outcome of the patients. Lungprotective ventilation also down regulates mechanosensitive pro-inflammatory pathways, resulting in reduced neutrophil accumulation in the alveoli and lower plasma levels of IL-6, IL-8, and TNF. ${ }^{[7,12]}$

\section{Prone ventilation}

Prone ventilation showed improvement in the level of oxygenation and thus improved the outcome in patients with ARDS having severe hypoxia. ${ }^{[13-15]}$ This effect is due to the reduction in the trans-pulmonary pressure gradient on making the patient prone, which helps in recruiting the collapsed areas of the lung without causing significant increase in the airway pressures. In the study by De Jong et al. (2013), prone ventilation was found to be a significantly effective in obese patients with ARDS than in non-obese patients. ${ }^{[16]}$

\begin{tabular}{ll}
\hline Table 1: Common risk factors for ARDS ${ }^{[4,5]}$ & \\
\hline Direct & Indirect \\
\hline Pneumonia & Non-pulmonary sepsis \\
Aspiration of gastric contents & Major trauma \\
Inhalation injury & Pancreatitis \\
Pulmonary contusion & Severe burns \\
Pulmonary vasculitis & Non-cardiogenic shock \\
Drowning & Drug overdose \\
& Multiple transfusions or transfusion associated acute lung injury (TRALI) \\
\hline
\end{tabular}




\section{Extracorporeal membrane oxygenation}

ECMO is an advanced circulatory and ventilatory support system, which is used to salvage the patients with refractory hypoxemia when the conventional treatment fails. The technique has been used successfully as a rescue therapy for the severe ARDS cases as shown by the CESAR trial in $2009{ }^{[17]}$. The evidence to support the use of ECMO as a primary treatment in ARDS is lacking and needs further research. ${ }^{[18,19]}$

\section{High-frequency oscillatory ventilation}

High-frequency oscillatory ventilation (HFOV) seemed ideal for lung protection in ARDS, but the OSCAR study concluded with no 30-day survival benefit or cost benefit in patients in whom HFOV was used ${ }^{[20]}$. The meta-analysis of randomized control trials (RCT) by Gu et al. (2014) also concluded that with use of HFOV, there was no improvement in survival in ARDS patients, although it had no increase the risk of barotrauma or hypotension and also reduced the risk of oxygenation failure. ${ }^{[21]}$

\section{Neuromuscular blockade}

Neuromuscular blocking agents (NMBAs) are commonly used in ARDS, but their use remains controversial. In recent meta-analysis and review, the use of short term NMBAs in ARDS patients have shown a beneficial outcome mainly by decreasing the barotrauma and ventilator-induced lung injury. ${ }^{[22,23]}$

\section{Fluid-conservative therapy}

In ARDS patients, due to increased alveolar vascular permeability, there is presence of alveolar edema, which may get worsened as a consequence of fluid overload. The conservative approach of fluid management in ARDS has been proven to be beneficial in reducing ventilator days but doesn't improve survival. ${ }^{[2]}$

\section{Intravenous $\beta-2$ agonist in ARDS}

The BALTI trial (2006) was a single center RCT, which showed the benefit of intravenous infusion of Salbutamol for 7 days in patients with ARDS, by causing significant reductions in extravascular lung water and plateau airway pressures ${ }^{[25]}$. Despite this, the recent evidence from the BALTI 2 trial, which is a multicenter RCT, showed no benefit of intravenous $\beta-2$ agonist (Salbutamol) in patients with ARDS and concluded that this may have significant detrimental effects with increase in mortality. ${ }^{[26]}$

\section{Corticosteroids in ARDS}

ARDS, despite being an acute lung inflammatory disease with involvement of diverse inflammatory cells and mediators, the use of anti-inflammatory corticosteroids have not shown improved survival. A systematic review and meta-analysis by Ruan et al. (2014), which included 8
RCTs and 10 cohort studies concluded that corticosteroids may be harmful in some patients and not to be routinely used in ARDS. ${ }^{[27]}$

\section{Experimental trials}

In experimental models of ARDS in rats, bone-marrow derived mesenchymal stem cells (MSCs) reduce the severity of ventilator-induced lung injury by enhancing the regeneration of lung tissue and its repair ${ }^{[28,29]}$. Studies have shown that MSCs could be of benefit by their property to reduce the production of inflammatory mediators, leukocyte infiltration, tissue injury, and pulmonary failure. ${ }^{[30]}$

\section{CONCLUSION}

There has been considerable research on ARDS in the past decade and better understanding of its pathogenesis. Despite this, the effective therapeutic measures to decrease mortality in ARDS seem to be low-tidal volume mechanical ventilation, prone ventilation for severe ARDS cases; and in life-threatening cases not responding to the conventional therapies, ECMO rescue technology serves as a bridge to recovery.

\section{Conflicts of interests}

The authors declare no conflicts of interest.

\section{REFERENCES}

1. ARDS Definition Task Force; Ranieri VM, Rubenfeld GD, Thompson BT, Ferguson ND, Caldwell E, et al. ARDS Definition Task Force. Acute respiratory distress syndrome: The Berlin Definition. JAMA 2012;307:2526-33.

2. Ashbaugh DG, Bigelow DB, Petty TL, Levine BE. Acute respiratory distress in adults. Lancet 1967;2:319-23.

3. Bernard GR, Artigas A, Brigham KL, Carlet J, Falke K, Hudson L, et al. The American-European Consensus Conference on ARDS: definitions, mechanisms, relevant outcomes, and clinical trial coordination. Am J Respir Crit Care Med 1994;149(3 pt 1):818-24.

4. Ware LB, Matthay MA. The acute respiratory distress syndrome. N Engl J Med 2000;342:1334-49.

5. Matthay MA, Zemans RL. The Acute Respiratory Distress Syndrome: Pathogenesis and Treatment. Annu Rev Pathol 2011;6:147-63.

6. The Acute Respiratory Distress Syndrome Network. Ventilation with lower tidal volumes as compared with traditional tidal volumes for acute lung injury and the acute respiratory distress syndrome. N Engl J Med 2000;342:1301-8.

7. Parsons PE, Eisner MD, Thompson BT, Matthay MA, Ancukiewicz M, Bernard GR, et al. Lower tidal volume ventilation and plasma cytokine markers of inflammationin patients with acute lung injury. Crit Care Med 2005;33:1-6

8. Meade MO, Cook DJ, Guyatt GH, Slutsky AS, Arabi YM, Cooper DJ, et al. Ventilation strategy using low tidal volumes, recruitment maneuvers, and high positive end-expiratory pressure for acute lung injury and acute respiratory distress syndrome: a randomized controlled trial. JAMA 2008;299:637-45 
9. Villar J, Kacmarek RM, Perez-Mendez L, Aguirre Jaime A. A high positive end-expiratory pressure, low tidal volume ventilatory strategy improves outcome in persistent acute respiratory distress syndrome: a randomized, controlled trial. Crit Care Med 2006;34:1311-18.

10. Briel M, Meade M, Mercat A, Brower RG, Talmor D, Walter SD, et al. Higher vs lower positive end-expiratory pressure in patients with acute lung injury and acute respiratory distress syndrome: systematic review and meta-analysis. JAMA 2010;303:865-73.

11. Needham DM, Colantuoni E, Mendez-Tellez PA, Dinglas VD, Sevransky JE, Dennison Himmelfarb CR, et al. Lung protective mechanical ventilation and two year survival in patients with acute lung injury: prospective cohort study. BMJ 2012; 344:e2124.

12. Ranieri VM, De Tullio R, Dayer JM, Brienza A, et al. Effect of mechanical ventilation on inflammatory mediators in patients with acute respiratory distress syndrome: a randomized controlled trial. JAMA 1999;282:54-61.

13. Guerin C, Reignier J, Richard JC, Beuret P, Gacouin A, Boulain T, et al. PROSEVA Study Group:Prone positioning in severe acute respiratory distress syndrome. N Engl JMed 2013; 368:2159-68.

14. Cornejo RA, Diaz JC, Tobar EA, Bruhn AR, Ramos CA, González $\mathrm{RA}$, et al. Effects of prone positioning on lung protection in patients with acute respiratory distress syndrome. Am J Respir Crit Care Med 2013;188:440-8.

15. Sud S, Friedrich JO, Adhikari NK, Taccone P, Mancebo J, Polli F, et al. Effect of prone positioning during mechanical ventilation on mortality among patients with acute respiratory distress syndrome: a systematic review and meta-analysis. CMAJ 2014;186:E381-90.

16. De Jong A, Molinari N, Sebbane M, Prades A, Futier E, Jung B, et al. Feasibility and effectiveness of prone position in morbidly obeseARDS patients: a case-control clinical study. Chest 2013;163:1554-61.

17. Peek GJ, Mugford M, Tiruvoipati R, Wilson A, Allen E, Thalanany MM, et al. CESAR trial collaboration Efficacy and economic assessment of conventional ventilatory support versus extracorporeal membrane oxygenation for severe adult respiratory failure (CESAR): a multicentre randomised controlled trial. Lancet 2009;374:1351-63.

18. Combes A, Bacchetta M, Brodie D, Müller T, Pellegrino V. Extracorporeal membrane oxygenation for respiratory failure in adults. Curr Opin Crit Care 2012;18:99-104.

19. Combes A, Bréchot N, Luyt CE, Schmidt M.What is the niche for extracorporeal membrane oxygenation in severe acute respiratory distress syndrome? Curr Opin Crit Care 2012;18:527-32.
20. Lall R, Hamilton P, Young D, Hulme C, Hall P, Shah S, et al. A randomised controlled trial and cost-effectiveness analysis of high-frequency oscillatory ventilation against conventional artificial ventilation for adults with acute respiratory distress syndrome. The OSCAR (OSCillation in ARDS) study. Health Technol Assess 2015;19:1-177.

21. Gu XL, Wu GN, Yao YW, Shi DH, Song Y. Is high-frequency oscillatory ventilation more effective and safer than conventional protective ventilation in adult acute respiratory distress syndrome patients? A metaanalysis of randomized controlled trials. Crit Care 2014;30:18:R111.

22. Alhazzani W, Alshahrani M, Jaeschke R, Forel JM, Papazian L, Sevransky $\mathrm{J}$, et al. Neuromuscular blocking agents in acute respiratory distress syndrome: a systematic review and meta-analysis of randomized controlled trials. Crit Care 2013;17:R43.

23. O'Gara B, Fan E, Talmor DS.Controversies in the Management of Severe ARDS: Optimal Ventilator Management and Use of Rescue Therapies. SeminRespirCrit Care Med 2015;36:823-34.

24. National Heart, Lung, and Blood Institute Acute Respiratory Distress Syndrome (ARDS) Clinical Trials Network, Wiedemann HP, Wheeler AP, Bernard GR, Thompson BT, Hayden D, et al. Comparison of two fluidmanagement strategies in acute lung injury. N Engl J Med 2006;354:256475.

25. Perkins GD, McAuley DF, Thickett DR, Gao F. The beta-agonist lung injury trial (BALTI): a randomized placebo-controlled clinical trial. Am J Respir Crit Care Med 2006;173:281-7.

26. Gao Smith F, Perkins GD, Gates S, Young D, McAuley DF, Tunnicliffe W, et al. Effect of intravenous $\beta-2$ agonist treatment on clinical outcomes in acute respiratory distress syndrome (BALTI-2): a multicentre, randomized controlled trial. Lancet 2012;379:229-35.

27. Ruan SY, Lin HH, Huang CT, Kuo PH, Wu HD, Yu CJ. Exploring the heterogeneity of effects of corticosteroids on acute respiratory distress syndrome: a systematic review and meta-analysis. Crit Care 2014;18:R63.

28. Curley GF, Hayes M, Ansari B, Shaw G, Ryan A, Barry F, et al. Mesenchymal stem cells enhance recovery and repair following ventilator-induced lung injury in the rat. Thorax 2012;67:496-501.

29. Chimenti L, Luque T, Bonsignore MR, Ramírez J, Navajas D, Farré R. Pre-treatment with mesenchymal stem cells reduces ventilator-induced lung injury. Eur Respir J 2012;40:939-48.

30. Xu F, Hu Y, Zhou J, Wang X. Mesenchymal stem cells in acute lung injury: are they ready for translational medicine? J Cell Mol Med 2013;17:927-35.

How to cite this article: Rawal G, Yadav S, Kumar R. Acute respiratory distress syndrome: An update and review. J TransI Intern Med 2018; 6: 74-7. 